\title{
BEHAVIOR OF PREFABRICATED BEAM-COLUMN CONNECTION WITH SHORT STRANDS IN SELF-CENTERING STEEL FRAME
}

\author{
Yan-xia Zhang 1, 2, 3, *, Quan-gang Li ${ }^{3}$, Wei-zhen Huang ${ }^{3}$, Kun Jiang ${ }^{3}$ and Yu Sun ${ }^{3}$ \\ ${ }^{1}$ Beijing Advanced Innovation Center for Future Urban Design, Beijing University of Civil Engineering and Architecture, Beijing, China \\ ${ }^{2}$ Beijing Higher Institution Engineering Research Center of Civil Engineering Structure and Renewable Material, Beijing University of Civil Engineering and Architecture, Beijing, Chine \\ ${ }^{3}$ School of Civil and Transportation Engineering, Beijing University of Civil Engineering and Architecture, Beijing, China \\ *(Corresponding author: E-mail: zhangyanxia@bucea.edu.cn)
}

\section{A B S T R A C T}

A prefabricated beam-column connection with short strands (SSPC) in self-centering steel frame was proposed in this paper. The connection connects the frame column with the short beam portions on both sides through short post-tensioned (PT) prestressed strands, thus having avoided on-site aerial tension and achieving a prefabricated connection. Two full-scale test specimens were designed; low cyclic loading quasi-static tests and numerical simulations were also conducted. The study indicated that the hysteresis loops of the prefabricated beam-column connection with short strands showed an obvious double-flag shape and displayed a significant self-centering feature and satisfying energy dissipation ability. Aside from the occurrence of plasticity of the beam flange reinforcing plates and the beam flange at the two SSPCs closer to the column, the strain at the locations was small, resulting in an elastic state. The results of the theoretical formula derivation, finite element analyses, and experiments were very consistent.
A R T I C LE H ISTORY

\begin{tabular}{|c|c|}
\hline Received: & 9 May 2018 \\
\hline Revised: & 8 October 2018 \\
\hline Accepted: & 14 October 2018 \\
\hline \multicolumn{2}{|c|}{ K E Y W O R D } \\
\hline \multicolumn{2}{|c|}{$\begin{array}{l}\text { Prefabricated beam-column } \\
\text { connection with short strands; } \\
\text { Low cyclic loading quasi-static } \\
\text { tests; } \\
\text { Self-centering steel frame; } \\
\text { Finite element analyses; } \\
\text { Theoretical formula derivation }\end{array}$} \\
\hline
\end{tabular}

\section{Introduction}

Typical moment connections in steel moment resisting frames often dissipate energy by developing plasticity and result in large residual drift, which will affect the normal structure functions and greatly increase the difficulties of post-seismic repair. An alternative steel moment connection introducing unbonded posttensioned technology to prestress the beams on to the columns was developed aimed at reducing the post-seismic residual deformation and achieving self-centering function of the structures. The early experimental research on self-centering steel frame connections was conducted by Garlock et al. [3]. Extensive investigations on self-centering beam-column connections with top and seat angles to provide energy dissipation were subsequently published by Ricles et al. [4-5] and Garlock et al. [6-8]. Later research mainly focused on the impact of energy dissipation devices on seismic behavior and self-centering performances, including energy dissipating bars proposed by Christopoulos et al. [9-10], frictional energy dissipation devices attached to both top and bottom flanges of the beam presented by Rojas et al. [11], attached to the bottom of the beam flange proposed by Wolski et al. [12], bolted web friction device proposed by Lin et al. [13-14] and viscous dampers studied by Tzimas A et. al. [15]. Latest researches toward self-centering steel moment connections included that adopting superelastic shape memory alloys (SMA) bolts conducted by Wang W. et. al [16] and that using a rigid node above and below the beam flanges completed by Ali Jahangiri et. al. [17]. However, the above self-centering steel moment-resisting frame connections require on-site aerial tension of the prestressed strands, which would bring great difficulties to construction. Zhang et al. [18-20] proposed a prefabricated self-centering beamcolumn connection with a bolted web friction device and a series of experiments and theoretical analyses have been carried out.

In this paper, another new prefabricated beam-column connection with short strands (SSPC) has been proposed, which can similarly achieve the selfcentering mechanism, restore the initial structural feasibility and dissipate seismic energy by web friction devices (WFD). Additionally, the tension of the prestressed strands on the ground of the construction site is possible and the beam-column connection only requires bolts in the assembly process. Thus, the construction difficulties would be reduced, and simultaneously the quality and assembly efficiency would be improved.

\section{Connection details}

The SSPC details are illustrated in Figure 1. The column is connected with both short beam portions by prestressing the eight high-strength steel strands; the intermediate beam portion is then assembled with short beam portion by splicing plates and high-strength bolts. And the energy dissipation device, WFD, is mainly achieved by adopting shear plates and high-strength bolts. The short beam web and the shear plate are connected with high-strength bolts; brass plates are sandwiched between them to ensure a stable friction behavior. Meanwhile, elongated circular holes are opened on the short beam web to allow the smooth slippage of high-strength bolts in the connection gap opening and closing processes.

The gap opening of the contact surface between the beam and the column is shown in Figure 2. The WFD dissipates energy by friction and thus prevents damage to the beams and columns. And the connection can restore to its original position upon unloading under the force of the prestressed strands.

\section{Theoretical formula derivations}

The ideal moment-gap opening rotation $\left(M-\theta_{r}\right)$ relation of a SSPC is shown in Figure 3. From the events 0 to 1 , the connection had an initial stiffness similar to the traditional welded moment connection. When the pressure upon gap opening at the interface between the beam and column was precisely zero; the stress of the prestressed strands was canceled, and thus, $M_{d}$ was the decompression moment. At Event 1, once the connection had overcome the imminent gap opening moment $\left(M_{I G O}\right)$, the beam tension flange lost contact with the shim plates at the column surface and gap opening occurs. $M_{I G O}$ is the sum of the decompression moment due to the initial stress of prestressed strands and the moment $M_{f}$ due to friction in the web friction device (WFD). From event 1 to 2, gap opening of the connection produced lead to the further elongation of the prestressed strand, and as a result the PT force of it increases. At Event 3, the gap opening reached its peak value, which led to the prestressed strand yielding. From event 2 to 4 , the unloading process was performed, in which the moment was reduced by $2 M_{f}$ for an opposite direction of the friction force in WFD, whereas a constant $\theta_{r}$ was maintained. From events 4 to 5 , unloading continued to develop until $\theta_{r}$ decreased to zero, i.e., the beam upper and lower flanges made contact with the shim plate at the column surface. Continued unloading between events 5 to 6 , reduced moment to zero, and the beam tension flange fully compressed on the shim plate (Deng et al. 2013). Loading in the opposite direction followed a similar process.

After the connection produce the gap opening (as shown in Figure 2), the moment M in the SSPC is provided by the PT force and the friction in the WFDs, respectively $M_{p t}$ and $M_{f}$ (Gandomi et. al. 2013), as follows Eq. 1:

$M=M_{f}+M_{p t}$ 


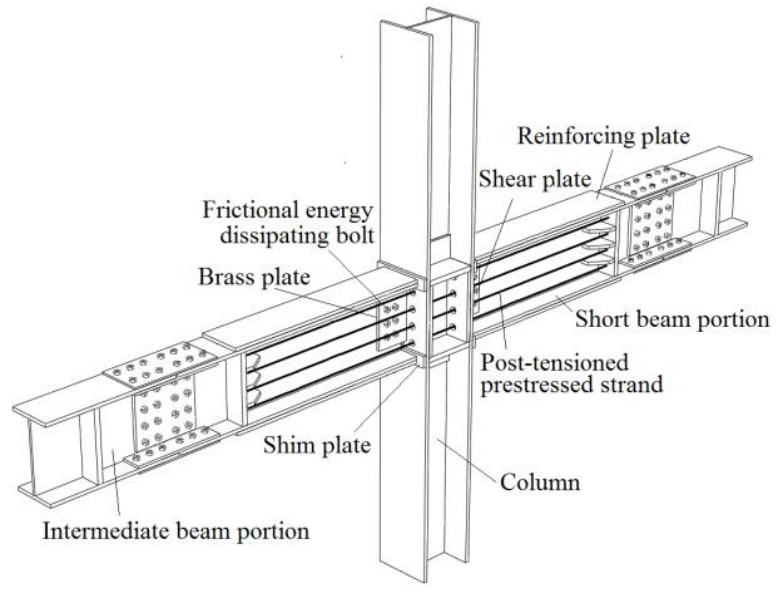

Fig. 1 SSPC details

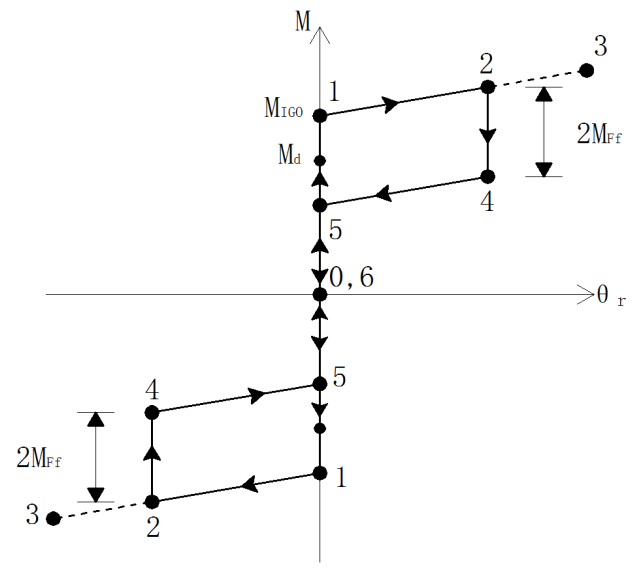

Fig. 3 Idealized $M-\theta_{r}$ behavior

$M_{\mathrm{f}}$ is expressed as Eq. 2:

$M_{f}=F_{f} r ; \quad F_{f}=n n_{f} \mu P$

Where $r$ is the distance from the rotation center to the centroid of the friction force, $\mu$ is the friction coefficient, $n$ is the number of high-strength bolts, $P$ is the pretension in each bolt, and $n_{f}$ is the total number of friction surfaces.

$M_{p t}$ is expressed as Eq. 3:

$M_{p t}=\sum_{i=1}^{n} F_{T i} H_{i}=F_{T} \cdot \frac{H_{b}}{2}$

Where $F_{T i}$ is the PT force of the $i_{\mathrm{th}}$ strand, $F_{T}$ is the total PT force of the strands, $H_{i}$ is the distance from $F_{T i}$ to the rotation center and $H_{b}$ is the beam depth.

$F_{T i}$ is expressed as Eq. 4 (Christopoulos et. al. 2002):

$F_{T i}=F_{T i 0}+\Delta F_{T i}$

Where $F_{T i 0}$ is the initial PT force, $\Delta F_{T i 0}$ refers to the increment of the PT force in the loading process.

Supposing the prestressed strands are uniformly arranged and the total increment of PT forces is equal to the beam axis force (Ricles et. al. 2010), the equilibrium equation is expressed as Eq. 5 (Collins et. al .2002):

$\sum_{i=1}^{n}\left[K_{s i}\left(\delta_{s i}-\delta_{b}\right)\right]=K_{b} \delta_{b} ; \quad \delta_{b}=\frac{\theta_{r} H_{b} \sum_{i=1}^{n} K_{s i}}{\sum_{i=1}^{n} K_{s i}+K_{b}}$

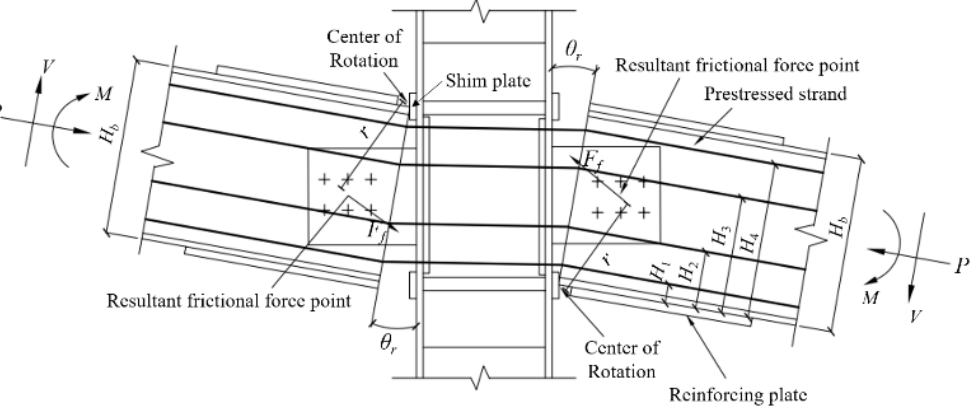

Fig. 2 Schematic of SSPC gap opening

Where $\delta_{s i}(i=1,2,3, \ldots, n)$ is the elongation of each strand as the gap opening rotation increases, $\delta_{b}$ is the axially compressed deformation of the beam. $K_{s i}$ is the stiffness of the $i_{\text {th }}$ strand, $K_{b}$ is the compressive stiffness of the beam.

$\Delta F_{T i}$ is expressed as Eq. 6

$\Delta F_{T i}=K_{s i}\left(\delta_{s i}-\delta_{b}\right)=K_{s i} \theta_{r}\left(H_{b}-\frac{H_{b} \sum_{i=1}^{n} K_{s i}}{\sum_{i=1}^{n} K_{s i}+K_{b}}\right)$

The reduction of the PT force was mainly induced by the sliding of the anchor clip and deformation of the anchorage end. Due to its larger diverging property, the clip-sliding amount was not considered in the theoretical calculations. The reduction of the PT force due to the anchorage end deformation was calculated by the following Eq. 7:

$F_{R T}=\Delta_{a} \frac{A_{s i} E_{s}}{l_{s i}}$

From the above, it is concluded that the sum of the PT force of all prestressed strands is derived as Eq. 8 follows:

$F_{T}=\sum_{i=1}^{n} F_{T i}=\sum_{i=1}^{n}\left(F_{T i 0}+\Delta F_{T i}-F_{R T}\right)=F_{T 0}+\frac{K_{b} \theta_{r} H_{b}}{\sum_{i=1}^{n} K_{s i}+K_{b}} \sum_{i=1}^{n} K_{s i}-\sum_{i=1}^{n}\left(\Delta_{a} \frac{A_{s i} E_{s}}{l_{s i}}\right)$

Where $F_{T 0}$ is the sum of the initial PT forces for all prestressed strands.

The moment caused by the tensile force $\left(M_{\mathrm{pt}}\right)$ according to the actual location of the prestressed strands can be expressed as Eq. 9 :

$M_{\mathrm{pt}}=\sum_{i=1}^{n} F_{T i} H_{i}=F_{T} \cdot \frac{H_{b}}{2}=\left[F_{T 0}+\frac{K_{b} \theta_{r} H_{b}}{\sum_{i=1}^{n} K_{s i}+K_{b}} \sum_{i=1}^{n} K_{s i}-\sum_{i=1}^{n}\left(\Delta_{a} \frac{A_{s i} E_{s}}{l_{s i}}\right)\right] \frac{H_{b}}{2}$

\section{Experimental program}

\subsection{Test Specimens}

Two test specimens, SSPC1 and SSPC2, were designed in this paper. The two test specimens have identical geometry except the initial PT force were $133 \mathrm{kN}\left(0.25 T_{\mathrm{y}}\right)$ and $162 \mathrm{kN}\left(0.3 T_{\mathrm{y}}\right)$, respectively, where $T_{\mathrm{y}}$ is the yielding PT force. The dimensions of the column and the beam were $350 \mathrm{~mm} \times 350 \mathrm{~mm} \times 16 \mathrm{~mm} \times 22 \mathrm{~mm}$ and $450 \mathrm{~mm} \times 250 \mathrm{~mm} \times 14 \mathrm{~mm} \times 20 \mathrm{~mm}$ respectively. Reinforcing plates were welded on both sides of the column flange, with a thickness of $16 \mathrm{~mm}$. The column stiffening rib and the shear plate was $30 \mathrm{~mm}$ and $20 \mathrm{~mm}$ thick, respectively. And the thickness of reinforcing plate welded on the outside faces of the beam flanges was $20 \mathrm{~mm}$. The six energy dissipation bolts were arranged in three rows and two columns, with a bolt specification of M20(10.9 property grade, nominal diameter of 20mm). The 
other dimensions can be seen in Figure 4. The prestressed strand was a $1 \times 19$ steel strand with a nominal diameter of $21.8 \mathrm{~mm}$.

\subsection{Material Properties}

The steel for both specimens adopts Q345B and the tensile testing results of the steel materials for both specimens are given in Table 1. The material properties for the prestressed strands are listed in Table 2. The friction coefficient between brass plate $(3 \mathrm{~mm})$ and steel plate is 0.34 according to the experimental results. Figure 5 shows the friction test for the brass plates.

\subsection{Test setup and loading scheme}

The low cyclic quasi-static tests of two specimens were conducted on a selfbalancing loading system. Test setup and test photograph is shown in Figure 6 and Figure 7 respectively. The length of the column was half the column height between two floors, i.e., the theoretical inflection point location. Hinge devices were installed on the upper and lower ends of the column so that the column ends could rotate freely in a horizontal plane without horizontal displacement. According to the test equipment conditions, the beam loading point was taken to be $2.3 \mathrm{~m}$ from the center of the column. The actuator at the top of the column was used to simulate the axial force of the column, based on the axial compression ratio of 0.2 . Two $100 t$ electro-hydraulic actuators were used on the two free ends of the cantilever beams for cyclic displacement loading.

The experimental loading scheme refers to the U.S. "Seismic Provisions for
Structural Steel Buildings" (AISC 341, 2005), controlling the loading process by story drift. Specific loading processes are as follows: (1)0.375\% rad, six cycles; (2)0.5\% rad, six cycles; (3)0.75\% rad, six cycles; (4) $1 \% \mathrm{rad}$, four cycles (5) $1.5 \% \mathrm{rad}$, two cycles; (6)2\%rad, two cycles; (7)3\% rad, two cycles; (8)4\% rad two cycles; (9)5\% rad, two cycles

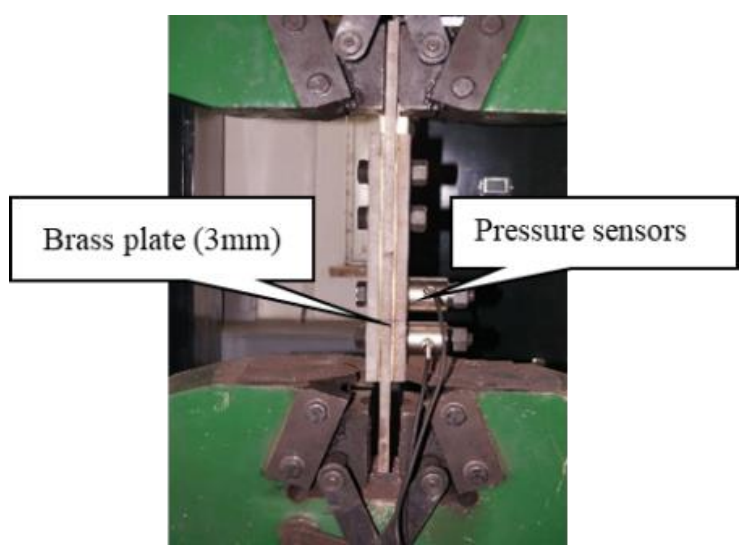

Fig. 5 Friction test of brass plates

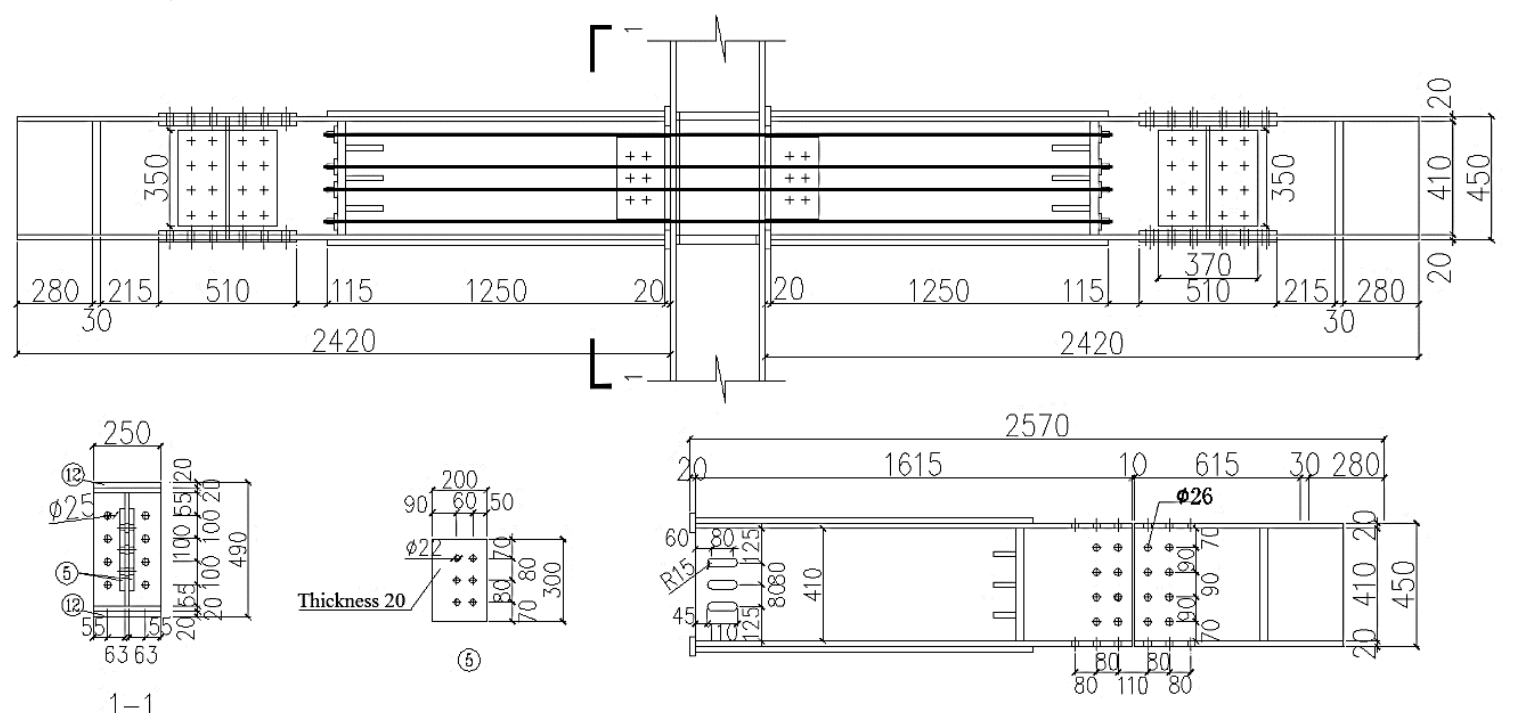

Fig. 4 Dimensions of SSPC specimens

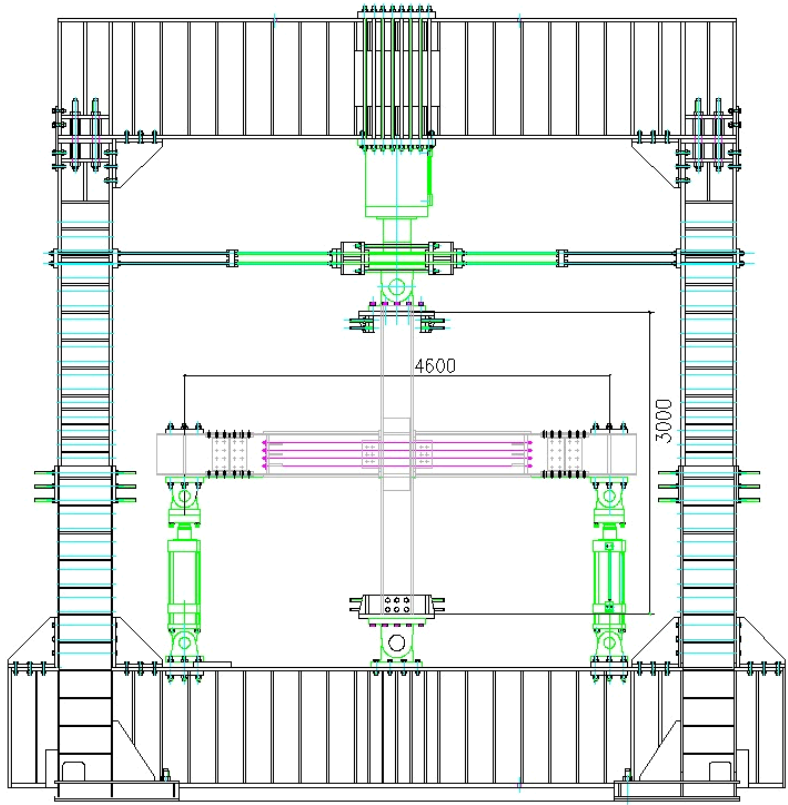

Fig. 6 Test setup

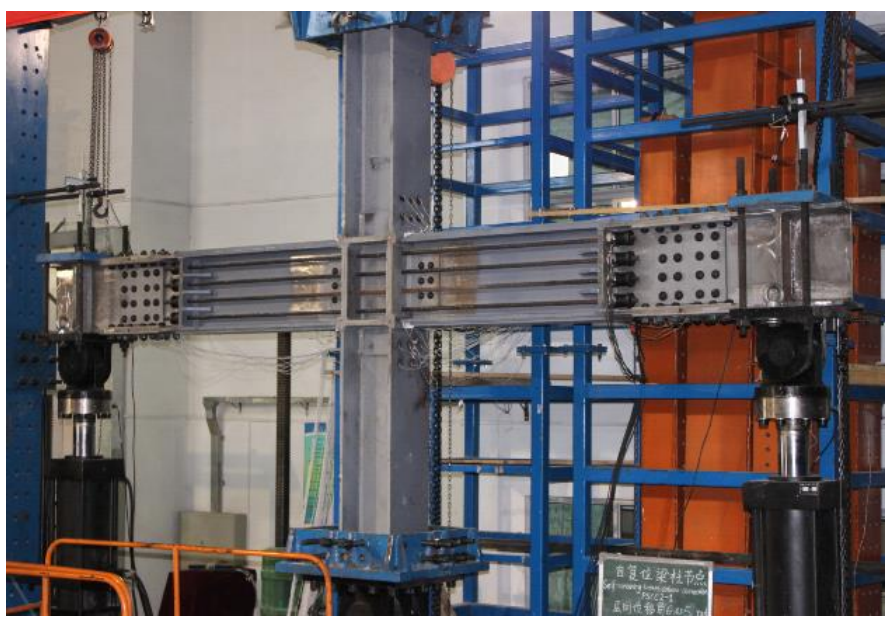


Table 1

Tensile testing results of standard samples

\begin{tabular}{ccccc}
\hline $\begin{array}{c}\text { Thickness } \\
(\mathrm{mm})\end{array}$ & $\begin{array}{c}\text { Yield strength } \\
(\mathrm{MPa})\end{array}$ & $\begin{array}{c}\text { Ultimate strength } \\
(\mathrm{MPa})\end{array}$ & $\begin{array}{c}\text { Percent elongation at fracture } \\
(\%)\end{array}$ & \multicolumn{2}{c}{ Elastic modulus } \\
\hline 14 & 384 & 561 & 27.0 & 2.15 \\
16 & 392 & 555 & 23.3 & 2.06 \\
18 & 381 & 555 & 25.3 & 2.22 \\
20 & 384 & 550 & 25.7 & 2.09 \\
22 & 388 & 574 & 26.8 & 1.42 \\
30 & 350 & 505 & 26.5 & 1.46 \\
\hline
\end{tabular}

Table 2

Prestressed strand material properties

\begin{tabular}{ccccc}
\hline Strand & Specimen & Yield strength (MPa) & Ultimate strength (MPa) \\
\hline & 1 & 1728.3 & 1894.5 \\
$1 \times 19$ & 2 & 1727.1 & 1895.8 & 2.03 \\
$1860 \mathrm{Mpa}$ & 3 & 1732.8 & 1729 & 1892 \\
\hline
\end{tabular}

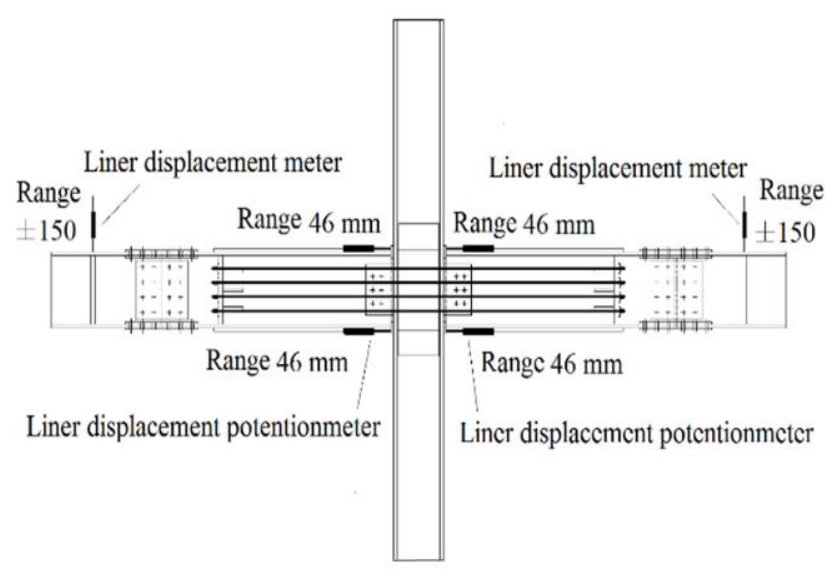

Fig. 8 Arrangement of displacement measurements

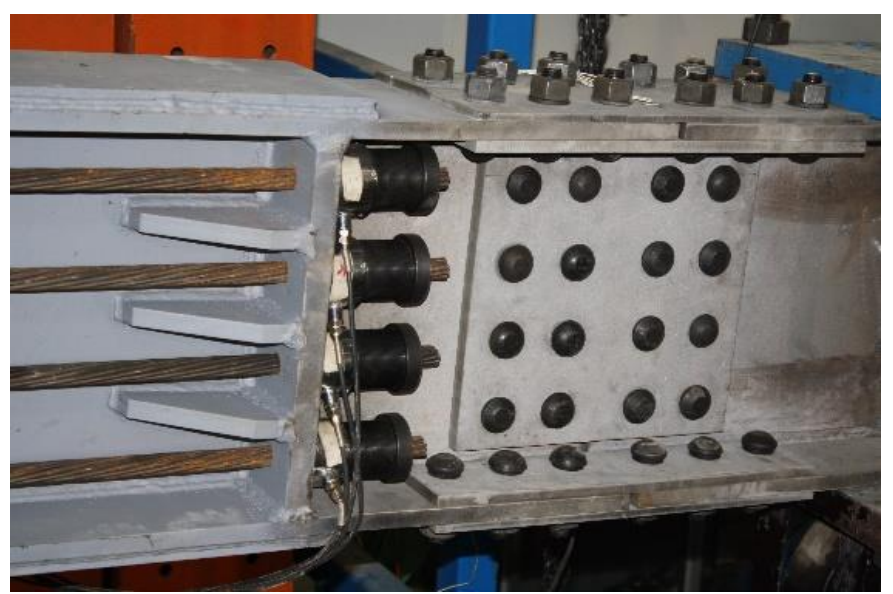

Fig. 9 PT force pressure sensors

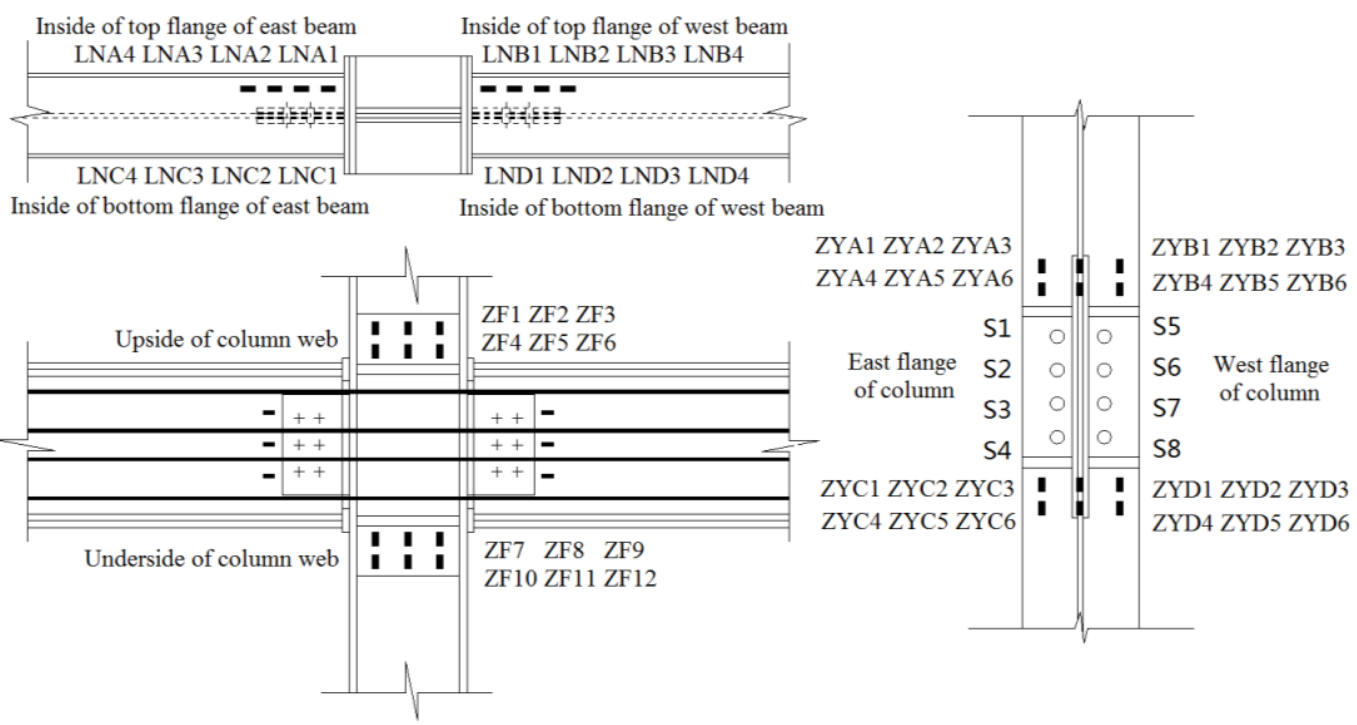

Fig. 10 Arrangement of strain gauges and prestressed strands of SSPC 


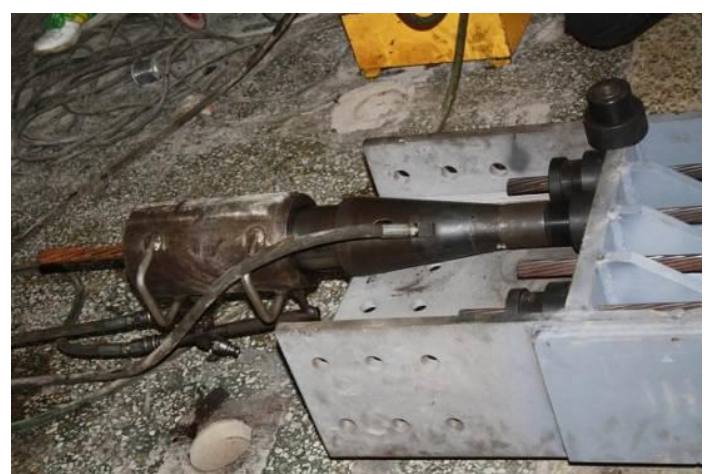

(a) Pre-tightening of the anchorage end

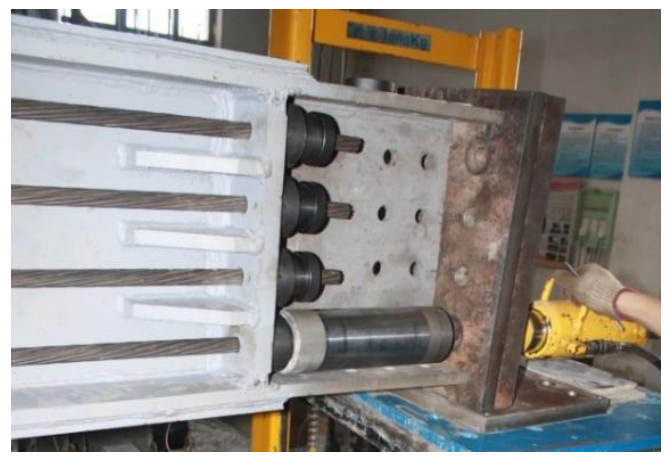

(c) Adjust PT force

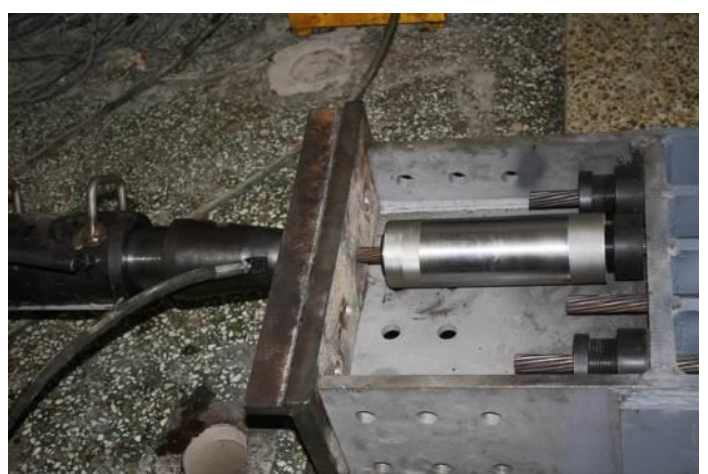

(b) Connecting transformation casing and pre-tightening of the tensioning anchor

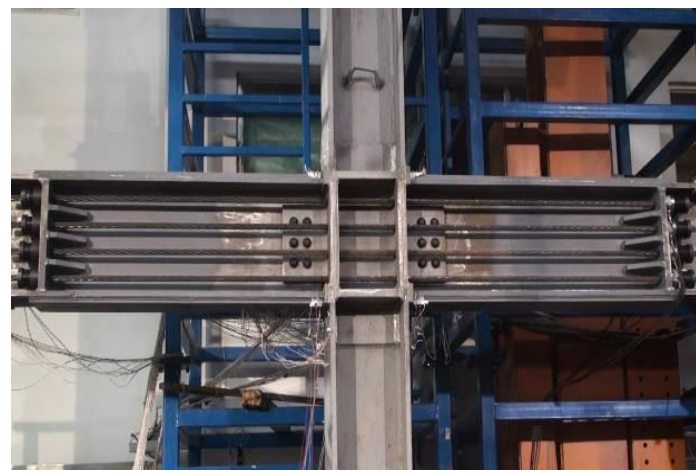

(d) Tensioning completed

Fig. 11 SSPCs prestressed tension process

\subsection{Instrumentation}

The experimental measurements include the strain distribution of the specimens, the displacement and reaction force of the beam ends, the gap opening and closing at the beam-column interface and the PT force. The displacement data for the beam ends are collected by two displacement meters arranged on the top flanges. The gap opening size at the beam-column interface was monitored by linear displacement potentiometers fastened on the upper and lower reinforced plates of the beam flanges, as shown in Figure 8. The PT force was measured by the $500 \mathrm{kN}$ pressure sensor anchored at the end of each prestressed strand, as shown in Figure 9. Strain gauges are pasted in various positions to measure the strain development during loading, as shown in Figure 10

\subsection{PT force of prestressed strands}

The prestressed strand was tensioned by a low retraction anchored tensioning method. The pressure sensor and anchorage were installed at the anchoring end first, and thus, the prestressed strand extruded from the anchor end with a $25-40 \mathrm{~mm}$ exposed length. A threaded anchorage was installed in the tensioning end, and the PT force was controlled by adjusting the rotation amount of the screw nut. Then, a jack was used to tighten the tensioning end to $450 \mathrm{kN}$, pre-tightening both the anchorage and tensioning ends to reduce the responding retraction of the anchor clip plate. After pre-tightening the end anchor, the prestressed strand was extended by a connection transformation device, and the pressure-bearing plates were placed on the end surface of the short beam portion, to establish a support surface at the beam end. Lastly, adjustment of the prestressed steel strands at the tensioning end was performed using a hydraulic jack, adjustable screw nut, and supporting reaction frame; the PT force of each prestressed steel strand was eventually adjusted to the predetermined value. The tensioning process and the overall post-tensioned specimens are shown in Figs. 11(a)-(d)

\section{Experimental results}

\subsection{Test Observations}

The experimental results are presented using SSPC1 as an example, and the experimental photographs of specimen SSPC1 are shown in Figs. 12(a)-(f).
When the story drift $(\theta)$ was between $0.00375 \mathrm{rad}$ and $0.0075 \mathrm{rad}$, the connection was similar to a rigid connection; when the story drift reached $0.0068 \mathrm{rad}$, a gap opening occurred at the beam-column interface. Afterward, the maximum gap opening width and bearing capacity of connection continued to increase with the story drift becoming larger. At the loading level of 0.02rad and 0.04rad, the corresponding gap opening width reached $6.65 \mathrm{~mm}$ and $16.64 \mathrm{~mm}$, respectively; and the corresponding bearing capacity was $251.56 \mathrm{kN}$ and $340.98 \mathrm{kN}$, separately. When the story drift reached $0.05 \mathrm{rad}$, the maximum gap opening width was $20.63 \mathrm{~mm}$, and the ultimate bearing capacity was $363.68 \mathrm{kN}$. Once the loading was complete, the connection was restored to the initial position, and the residual opening width was $0.94 \mathrm{~mm}$.

The deformation trend of the specimen SSPC2 during the loading process was basically same as that of SSPC1. Due to the fact that the initial PT force in SSPC2 was higher than that in SSPC1, the gap-opening was relatively delayed; the beam-column contacting surfaces disengaged when the story drift reached $0.0077 \mathrm{rad}$. The maximum opening width of SSPC2 reached $18.94 \mathrm{~mm}$, which was slightly smaller than that of SSPC1; the ultimate bearing capacity was $385.04 \mathrm{kN}$. The residual opening width of both connections was quite small, $0.94 \mathrm{~mm}$ and $0.21 \mathrm{~mm}$, respectively. Both connections achieved the selfcentering function.

\subsection{Hysteresis character and energy dissipation capability}

Figure 13(a)-(b) and Figure 14(a)-(b) show the hysteresis loops of the gap opening rotation $\theta_{r}$ and story drift $\theta$ versus the moment $M$, respectively. $M$ is the moment developed at the beam-column interface under the applied displacement loading.

The hysteresis loops of both SSPCs presented an obvious double flag shape and showed obvious self-centering characteristics. The hysteresis character with regard to gap opening for both connections was similar to that for a rigid connection but with higher stiffness and both connections remained in an elastic state. As the story drift continued to increase, a gap opening appeared between the beam and column, and the post-opening stiffness was decreased. The experimental results of the specimens are given in Table 3. As the initial PT force of the test specimen increased from $0.25 T_{\mathrm{y}}$ to $0.30 T_{\mathrm{y}}$, the gap-opening was gradually delayed; the imminent gap opening moment $M_{\mathrm{IGO}}$ increased from $356.87 \mathrm{kN} \cdot \mathrm{m}$ to $412.27 \mathrm{kN} \cdot \mathrm{m}$; the maximum moment at $0.05 \mathrm{rad} M_{0.05}$ increased from $772.82 \mathrm{kN} \cdot \mathrm{m}$ to $818.21 \mathrm{kN} \cdot \mathrm{m}$; and the effective energy dissipation coefficient $\beta_{\mathrm{E}}$ decreased from 0.436 to 0.408 . Both values satisfied the basic 
requirement of $\beta_{\mathrm{E}}>0.25$. The residual gap opening rotation upon unloading was $0.204 \%$ and $0.045 \%$, respectively, showing that a higher initial PT force resulted in a lower residual rotation. However, both residual rotations were at a relatively low level, indicating that the SSPCs possess excellent self-centering capability.

In summary, for the SSPCs, as the initial PT force of the connections increased, the initial and post-opening stiffness of the connections, imminent gap-opening moment and maximum PT force all increased to certain extents; furthermore, the maximum gap opening width gradually decreased, and the energy dissipation ability showed a decreasing trend. Both test specimens in the experiment satisfied the basic requirement of an energy dissipation coefficient is greater than 0.25 .

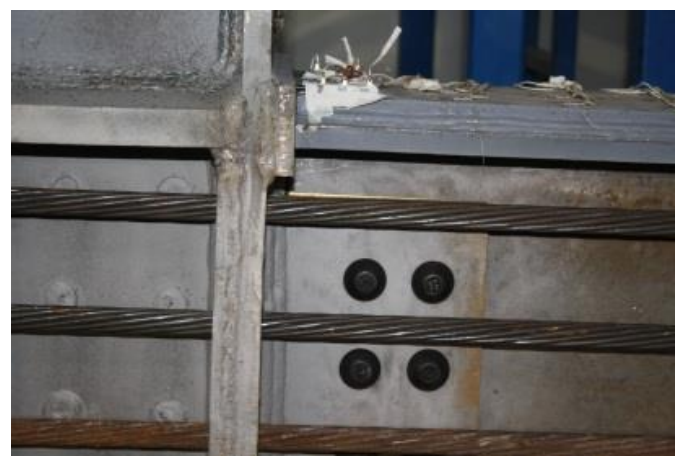

(a) $\theta=0.68 \%$,gap opening width $1.02 \mathrm{~mm}\left(\theta_{r}=0.219 \%\right)$

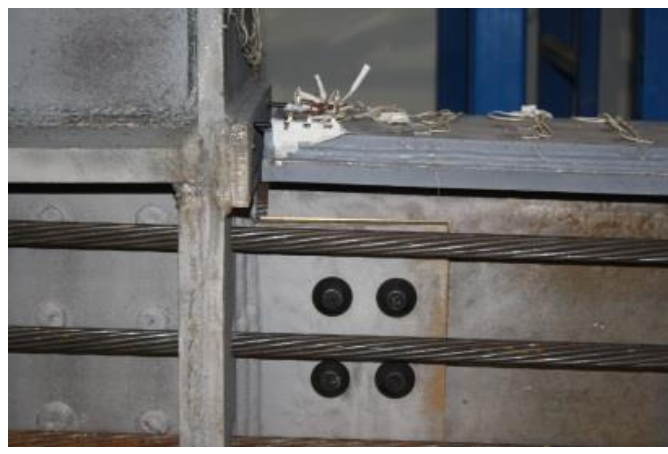

(c) $\theta=3 \%$,gap opening width $11.35 \mathrm{~mm}\left(\theta_{r}=2.435 \%\right)$

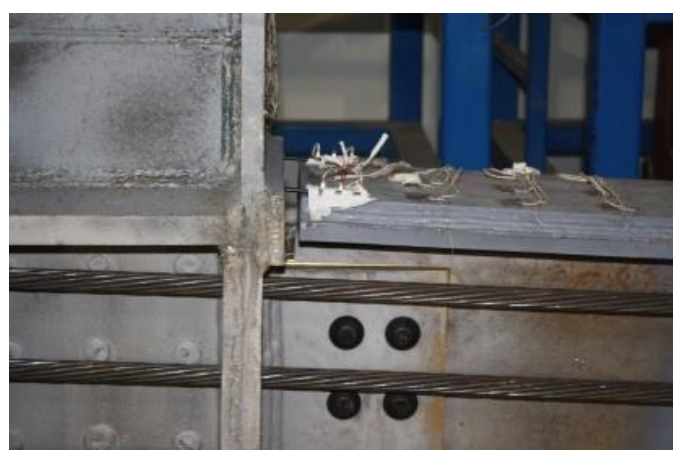

(e) $\theta=5 \%$,gap opening width $20.63 \mathrm{~mm}\left(\theta_{r}=4.426 \%\right)$

\subsection{Variations of PT force}

The PT force-story drift loops for S5 (as shown in Figure 10) of Specimens SSPC1 and SSPC2 are shown in Figure 15(a)-(b).

Figure 15(a)-(b) demonstrate that the PT force gradually increases after the gap opening occurs. When the story drift returned to zero, the PT force basically returned to the initial prestressing level; however, the PT force would decrease to a certain extent due to factors such as retraction of the core wire of the prestressed steel strand and sliding of the anchor clips.

Detailed data are listed in Table 4. The results show that the maximum PT

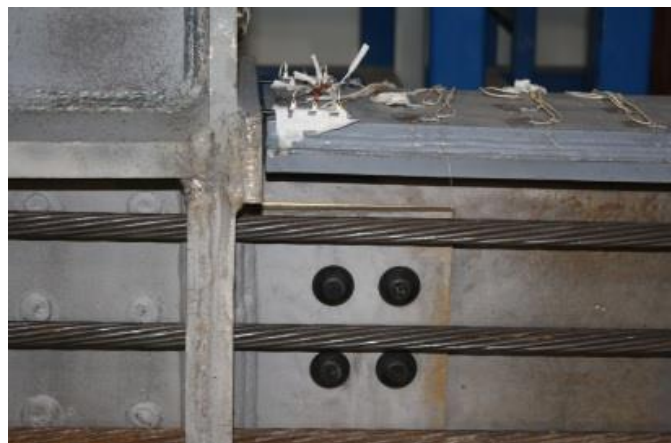

(b) $\theta=2 \%$,gap opening width $6.65 \mathrm{~mm}\left(\theta_{r}=1.427 \%\right)$

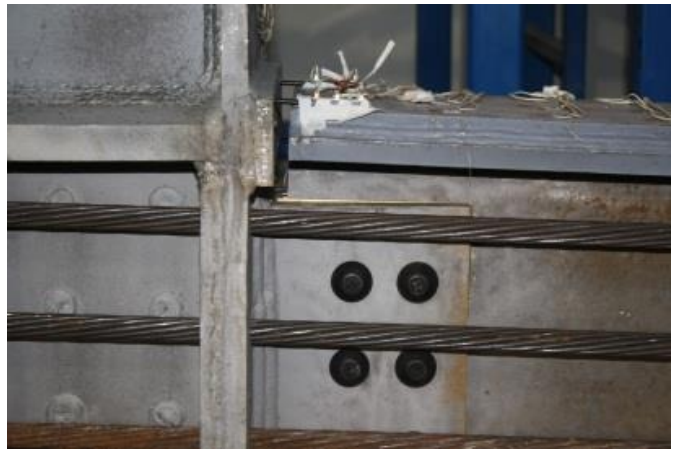

(d) $\theta=4 \%$,gap opening width $16.14 \mathrm{~mm}\left(\theta_{r}=3.463 \%\right)$

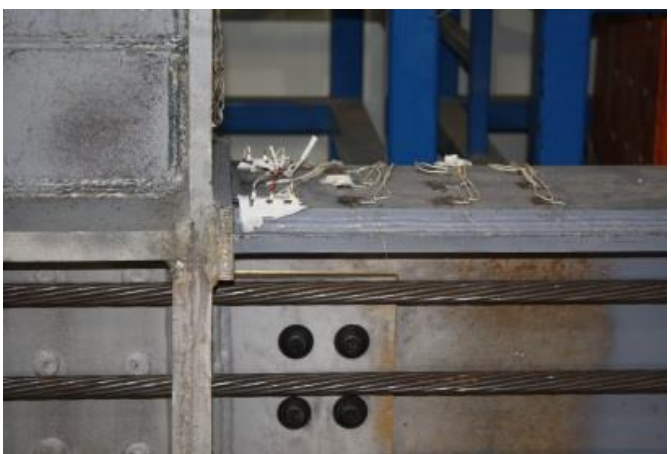

(f) Return to initial position, residual opening width $0.94 \mathrm{~mm}\left(\theta_{r}=0.204 \%\right)$

Fig. 12 Test process of specimen SSPC1

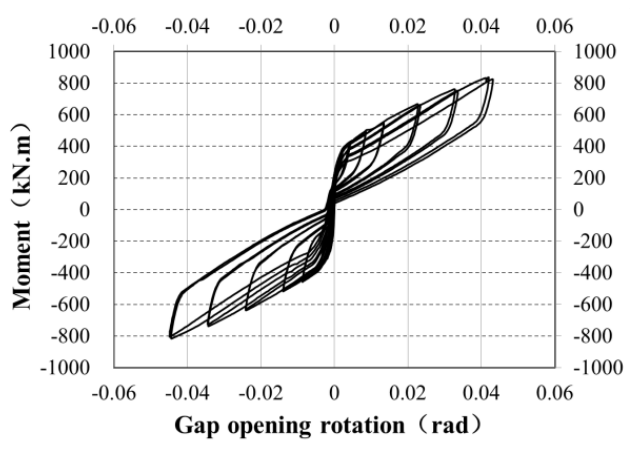

(a) SSPC1

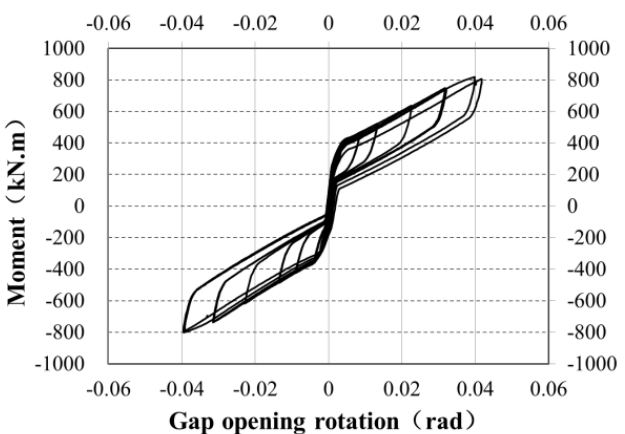

(b) SSPC2

Fig. 13 Moment-gap opening rotation response for both Specimens 


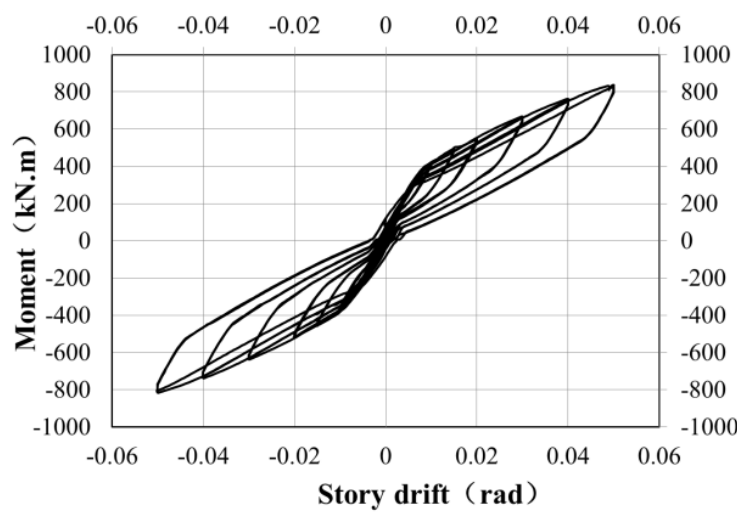

(a) SSPC1

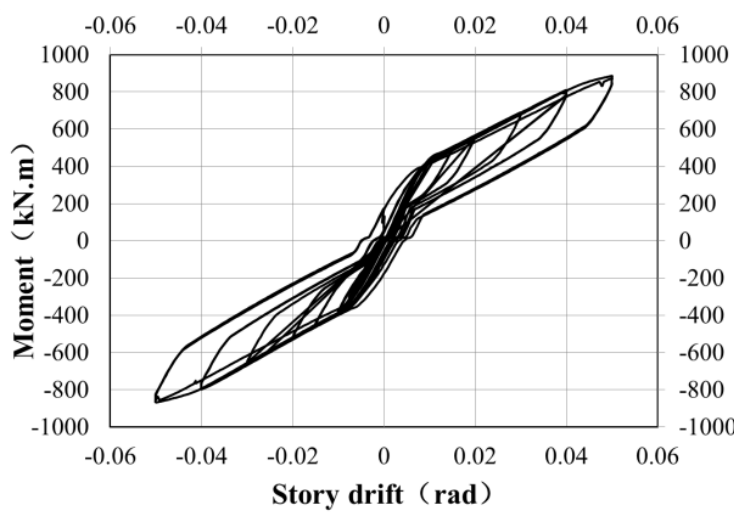

(b) SSPC2

Fig. 14 Moment-story drift response for both Specimens

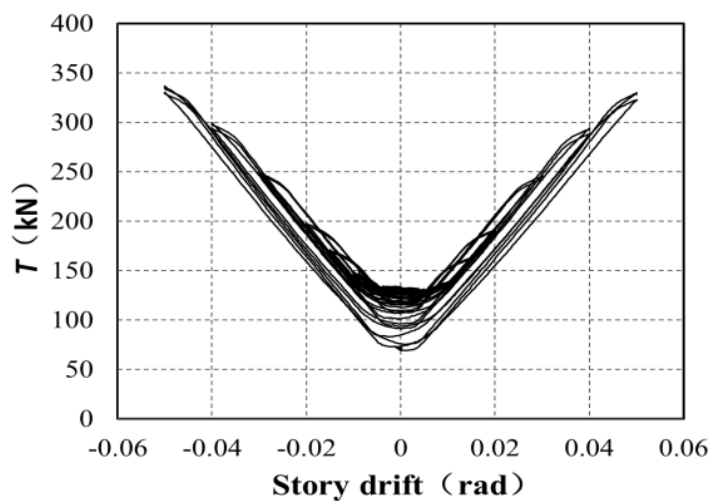

(a) SSPC1

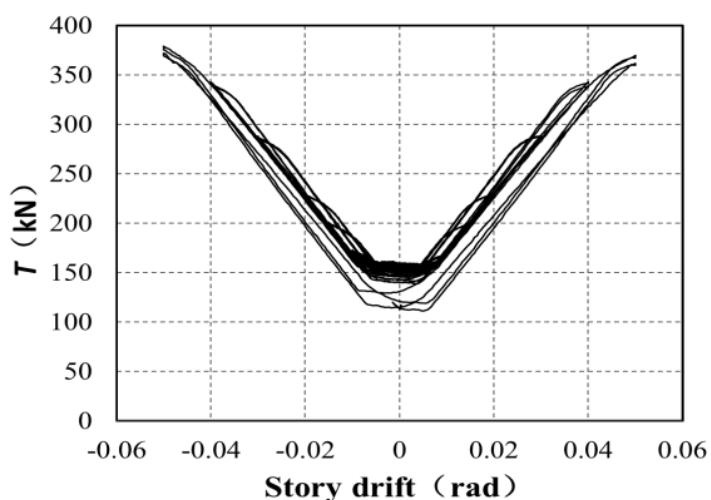

(b) $\mathrm{SSPC} 2$

Fig. 15 PT force-story drift curves of S5 of Specimens

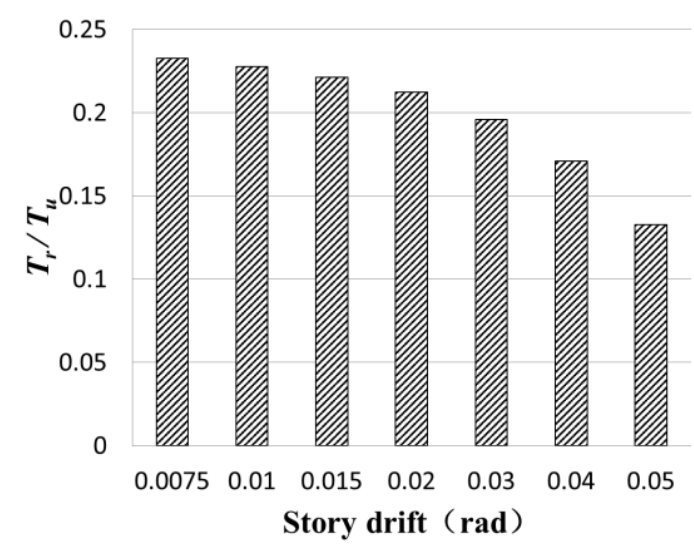

(a) SSPC1

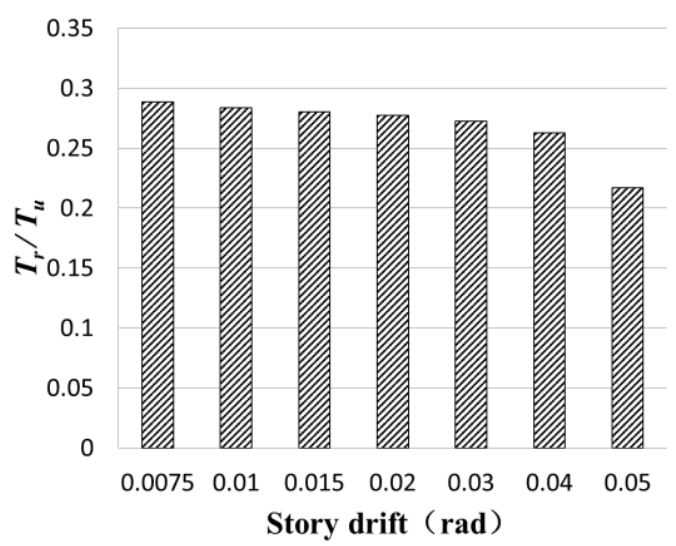

(b) SSPC2

Fig. 16 PT force reduction of Specimens

Table 3

Experimental Results of both SSPCs

\begin{tabular}{cccccccc}
\hline Specimens & $T_{0} / T_{\mathrm{y}}$ & $\theta_{\mathrm{IGO}}(\% \mathrm{rad})$ & $M_{\mathrm{IGO}}(\mathrm{kN} \cdot \mathrm{m})$ & $\theta_{\max }(\% \mathrm{rad})$ & $\mathrm{M}_{0.05}(\mathrm{kN} \cdot \mathrm{m})$ & $\beta_{\mathrm{E}}$ & $\theta_{\mathrm{res}}(\% \mathrm{rad})$ \\
\hline SSPC1 & 0.25 & 0.68 & 356.87 & 4.426 & 772.82 & 0.436 & 0.204 \\
SSPC2 & 0.30 & 0.77 & 412.27 & 4.064 & 818.21 & 0.408 & 0.045 \\
\hline
\end{tabular}

Where $T_{\mathrm{y}}$ : yielding PT force, $T_{\mathrm{y}}=540 \mathrm{kN} ; T_{0}$ : initial PT force; $\theta_{\mathrm{IGO}}$ : story drift when imminent gap-opening occurs; $M_{\mathrm{IGO}}$ : imminent gap-opening moment; $\theta_{\text {max }}:$ maximum gap opening rotation; $M_{0.05}:$ maximum moment when $\theta=5 \%$ rad; $\beta_{\mathrm{E}}$ : effective energy dissipation coefficient; $\theta_{\text {res }}:$ maximum residual rotation. 
force of the eight prestressed strands of SSPC1 and SSPC2 were $0.70 T_{\mathrm{y}}$ and $0.77 T_{\mathrm{y}}$, respectively. Both values were lower than the designed yield PT force $T_{\mathrm{y}}$; thus, normal function of the prestressed strand is guaranteed. As shown in Figure 16(a)-(b), the vertical axis is the ratio of the average PT force to the yielded PT force in each loading cycle; the horizontal axis refers to the corresponding story drift. Reduction of the SSPC1 PT force was mainly concentrated after the story drift reaching $0.02 \mathrm{rad}$. When it was at $0.02 \mathrm{rad}$, the PT force reduction rate was $15 \%$; the reduction rate increased rapidly to $22 \%$, $32 \%$, and $46 \%$ at $0.03 \mathrm{rad}, 0.04 \mathrm{rad}$, and $0.05 \mathrm{rad}$, respectively. For SSPC 2 , the PT force reduction rate was $7.5 \%$ when the story drift was $0.02 \mathrm{rad}$, and it increased to $9 \%, 12 \%$, and $27 \%$ when the story drift reached $0.03 \mathrm{rad}, 0.04 \mathrm{rad}$, and $0.05 \mathrm{rad}$, respectively. The PT force reduction was mainly concentrated after the story drift of $0.03 \mathrm{rad}$.

\subsection{Strain analysis}

Figure 17(a)-(d) showed that the beam flange reinforcing plate and the inside of beam flange in both SSPCs entered a plastic state; under the same story drift, the strain was gradually reduced as the distance to the column flange increased. In addition to the plasticity development closer to the column flange, the other regions are all in an elastic state.

The typical strain values of the column web and flange of the two SSPCs were relatively small (as shown in Figure 18(a)-(d), indicating that the column web reinforcing plate could effectively reduce the strain level at regions of the column web and that no residual strain was produced after returning to the initial position.

Table 4

Experimental Results of PT Forces

\begin{tabular}{|c|c|c|c|c|c|c|}
\hline \multirow{2}{*}{ Specimens } & \multicolumn{3}{|c|}{ SSPC1 } & \multicolumn{3}{|c|}{ SSPC2 } \\
\hline & $T_{\max } / T_{\mathrm{y}}$ & $T_{\mathrm{r}} / T_{\mathrm{y}}$ & $\left(T_{0}-T_{\mathrm{r}}\right) / T_{0}$ & $T_{\max } / T_{\mathrm{y}}$ & $T_{\mathrm{r}} / T_{\mathrm{y}}$ & $\left(T_{0}-T_{\mathrm{r}}\right) / T_{0}$ \\
\hline S1 & 0.69 & 0.13 & $46 \%$ & 0.75 & 0.23 & $24 \%$ \\
\hline S2 & 0.7 & 0.14 & $42 \%$ & 0.76 & 0.23 & $22 \%$ \\
\hline S3 & - & - & - & - & - & - \\
\hline S4 & 0.71 & 0.16 & $35 \%$ & 0.77 & 0.25 & $16 \%$ \\
\hline S5 & 0.62 & 0.13 & $45 \%$ & 0.7 & 0.21 & $27 \%$ \\
\hline S6 & 0.66 & 0.12 & $51 \%$ & 0.72 & 0.19 & $36 \%$ \\
\hline S7 & 0.66 & 0.12 & $51 \%$ & 0.73 & 0.21 & $30 \%$ \\
\hline S8 & 0.68 & 0.11 & $54 \%$ & 0.71 & 0.21 & $30 \%$ \\
\hline Average value & 0.67 & 0.13 & $46 \%$ & 0.65 & 0.22 & $26 \%$ \\
\hline
\end{tabular}

$T_{\mathrm{r}}$ : residual PT force; $T_{\max }$ : maximum PT force; “_-”: Error data acquisition

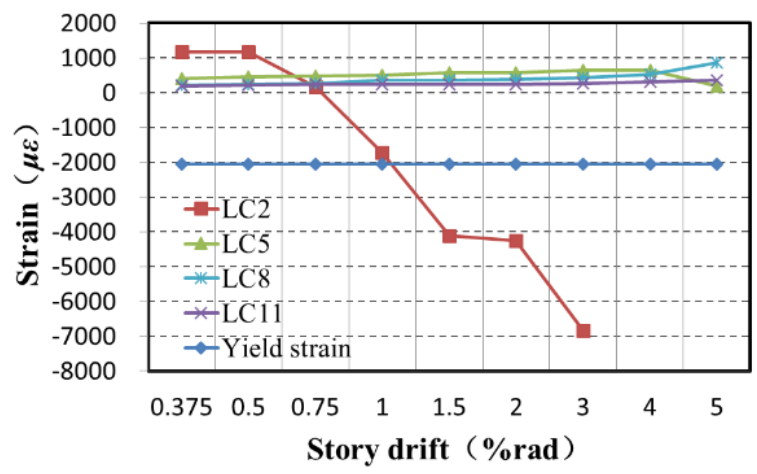

(a) Beam flange reinforcing plate of SSPC1

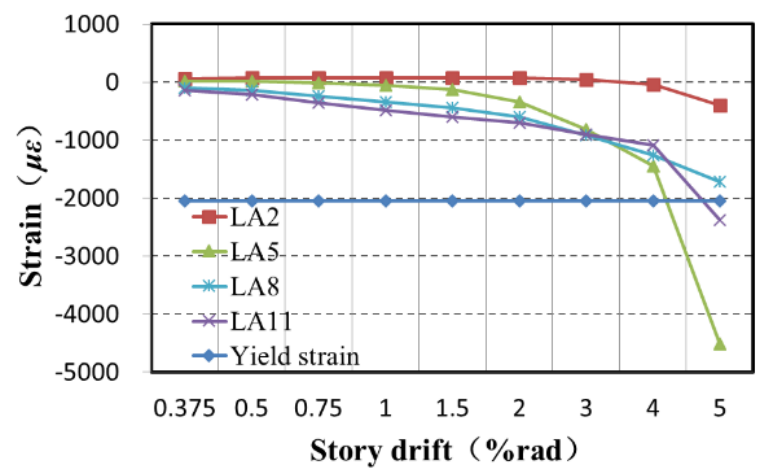

(c) Beam flange reinforcing plate of SSPC2

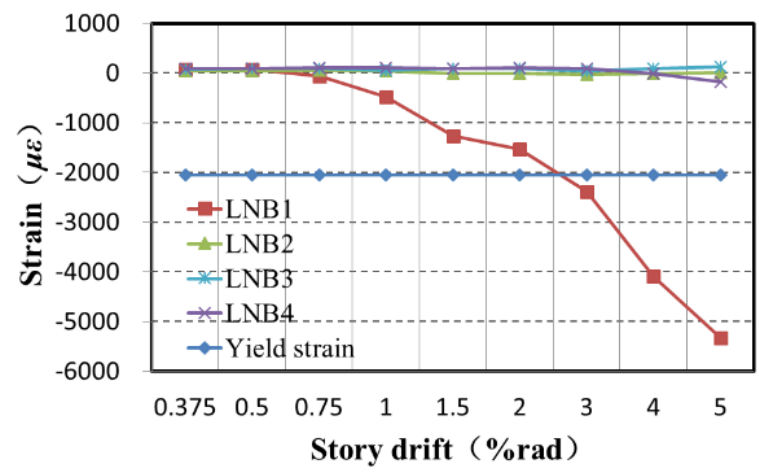

(b) Inside of beam flange of SSPC1

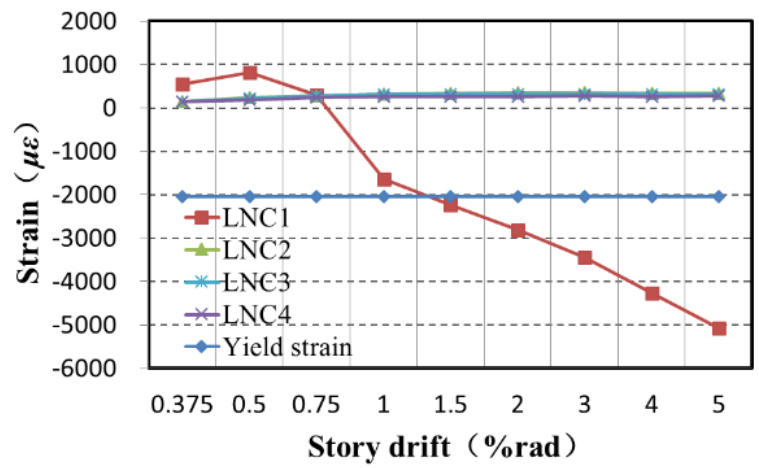

(d) Inside of beam flange of SSPC2

Fig. 17 Strain of different positions of SSPCs beam 


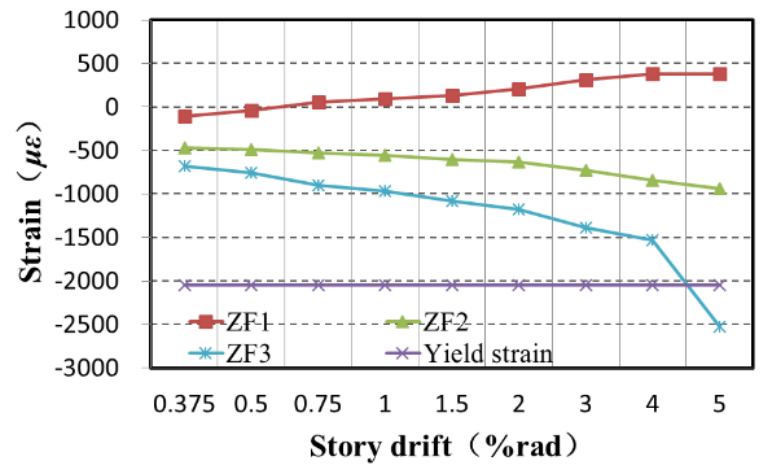

(a) Column web of SSPC1

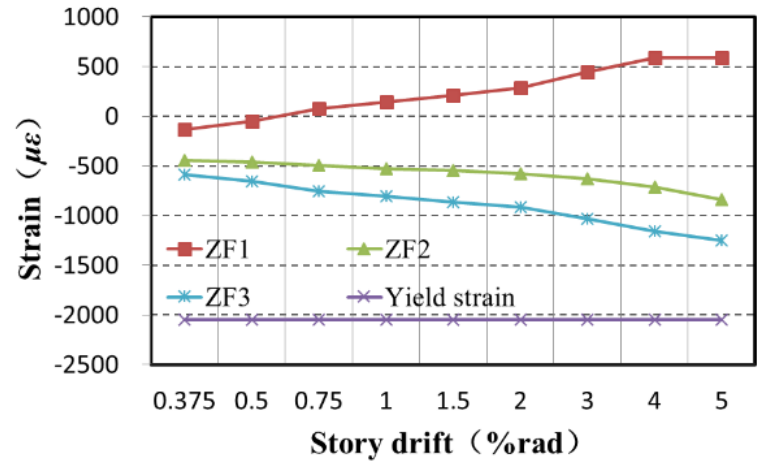

(c) Column web of SSPC2

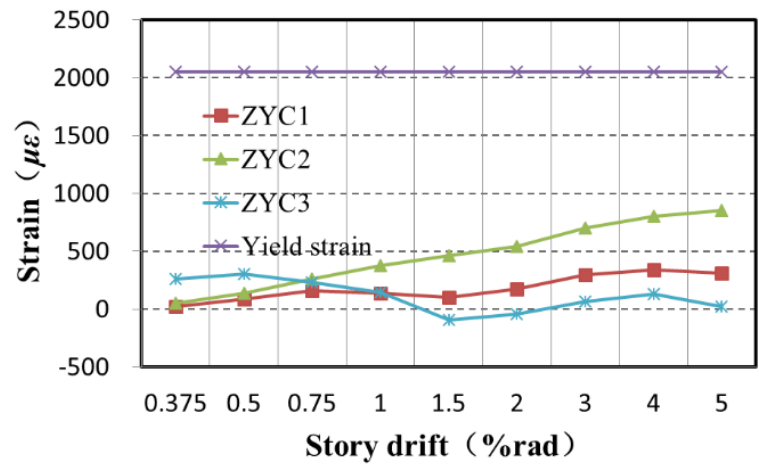

(b) Column flange of SSPC1

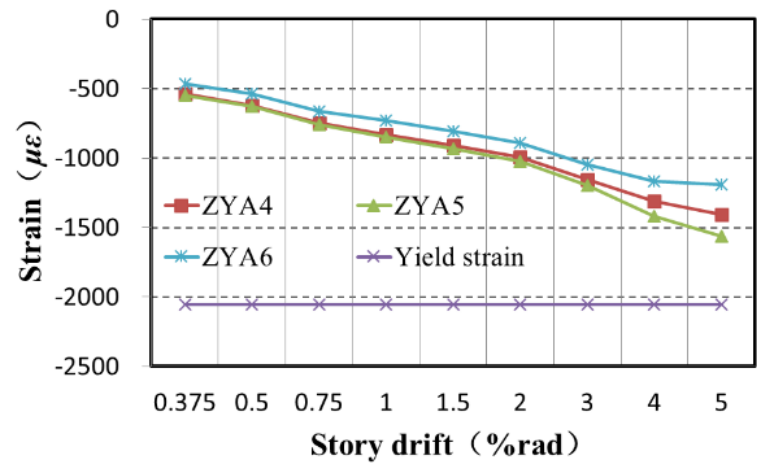

(d) Column flange of SSPC2

Fig. 18 Strain of different positions of SSPCs column

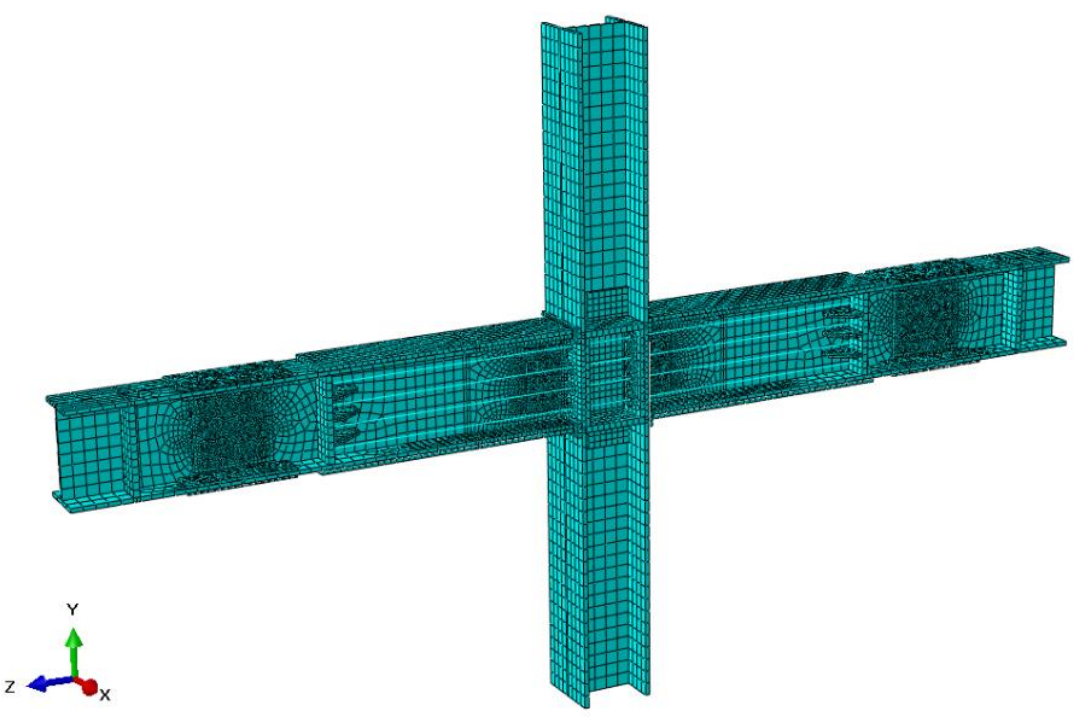

Fig. 19 Finite element model of SSPCs

\section{Finite element analysis (FEA) and theoretical calclulation of the} SSPCs

\subsection{Establishment of finite element model}

Based on the completed experiments, the finite element analysis (FEA) of SSPCs was conducted by Software Abaqus6.11. The finite element model of SSPC and its grid arrangement can be seen in Figure 19. In the modelling process, the impact of geometric and material nonlinearities was considered.

The steel material used for the test specimens was Q345B, for which the elastic property was defined by the Elastic modulus $(E)$ and Poisson's ratio $(v)$, and the plastic property was given in the form of a stress-strain relation. The steel materials did not enter a reduction stage in the material test; thus the stressstrain relation only used an enhanced bilinear model. According to the steel material test data, $\sigma_{\mathrm{y}}=392 \mathrm{~N} / \mathrm{mm}^{2}, \varepsilon_{\mathrm{y}}=0.19 \%, \sigma_{\mathrm{u}}=555 \mathrm{~N} / \mathrm{mm}^{2}, \varepsilon_{\mathrm{u}}=22.0 \%$, the elastic modulus $E=206000 \mathrm{Mpa}$ and the Poisson's ratio of $v=0.3$ were used. The prestressed strands were in elastic state, and thus, only the Elastic modulus $E=2.03 \mathrm{GPa}$ and the Poisson's ratio $v=0.3$ were defined.

The main body of the finite element model for SSPCs adopted C3D8R solid element, and the post-tensioned strands selected T3D3 truss unit. In consideration of the calculation accuracy and efficiency, the global seed spacing for grid of FEA model selected $200 \mathrm{~mm}$, the reinforced plate of the beam flange and the shear plate at beam web selected $60 \mathrm{~mm}$ and $30 \mathrm{~mm}$, respectively. The six degrees of freedom for column foot were restrained to simulate a rigid connection and the two lateral degrees of freedom at the column top were also restrained to allow the axial deformation of column under the action of axial load.

The loading process was simulated by imposing certain displacement to the both beam ends and the loading scheme was same as that of the experiment, that is: (1) $0.375 \% \mathrm{rad}$, six cycles; (2) $0.5 \% \mathrm{rad}$, six cycles; (3) $0.75 \% \mathrm{rad}$, six cycles; (4) $1 \% \mathrm{rad}$, four cycles; (5) $1.5 \% \mathrm{rad}$, two cycles; (6)2\% rad, two cycles; (7)3\% rad, two cycles; (8)4\% rad, two cycles; (9)5\% rad, two cycles. 


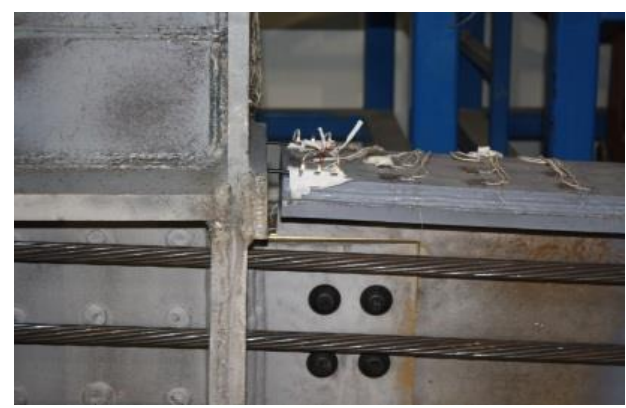

(a) $\theta=5 \%$, gap opening width $20.63 \mathrm{~mm}(\theta \mathrm{r}=4.426 \%)$

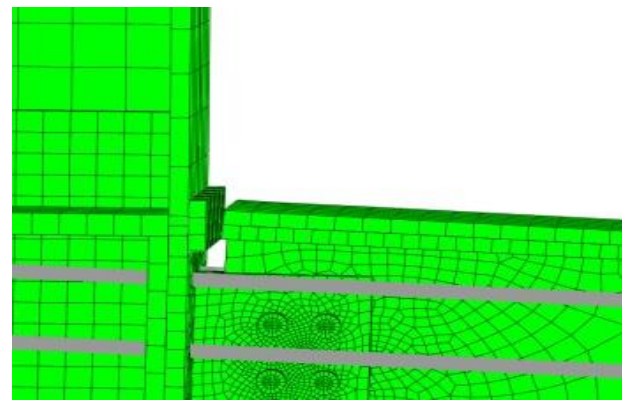

(c) $\theta=5 \%$, gap opening width $19.97 \mathrm{~mm}(\theta \mathrm{r}=4.285 \%)$

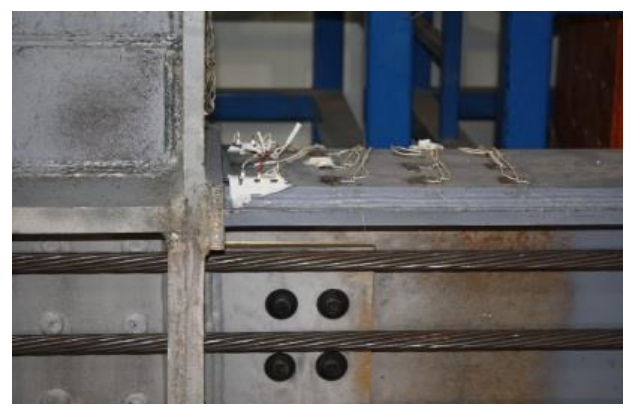

(b) Return to equilibrium position, residual opening width $0.94 \mathrm{~mm}(\theta \mathrm{r}=0.204 \%)$

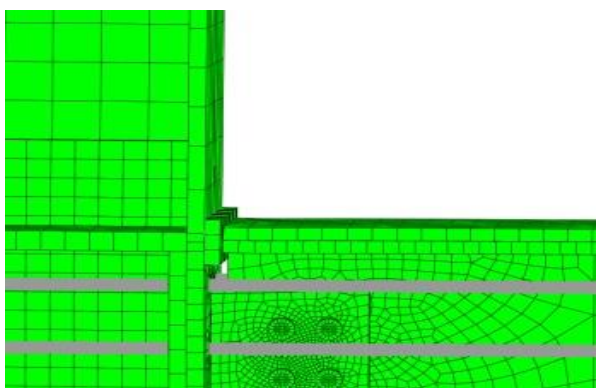

(d) Return to equilibrium position, residual opening width $0.10 \mathrm{~mm}(\theta \mathrm{r}=0.023 \%)$

Fig. 20 Experimental and FEA deformation diagram of SSPC1

Table 5

Experimental and FEA results

\begin{tabular}{|c|c|c|c|c|c|c|}
\hline \multicolumn{2}{|c|}{ Specimens } & \multirow{2}{*}{$\frac{\theta_{\mathrm{IGO}}(\mathrm{rad})}{0.68 \%}$} & \multirow{2}{*}{$\frac{\text { Initial opening width }(\mathrm{mm})}{1.02}$} & \multirow{2}{*}{$\frac{\text { Maximum opening width }(\mathrm{mm})}{20.63}$} & \multirow{2}{*}{$\begin{array}{c}\text { Maximum residual opening width }(\mathrm{mm}) \\
0.94\end{array}$} & \multirow{2}{*}{$\frac{\text { Ultimate bearing capacity }(\mathrm{kN})}{363.68}$} \\
\hline & Test & & & & & \\
\hline & FEA & $0.6 \%$ & 1.38 & 19.97 & 0.10 & 384.43 \\
\hline \multirow{2}{*}{ SSPC2 } & Test & $0.77 \%$ & 1.05 & 18.94 & 0.21 & 385.04 \\
\hline & FEA & $0.8 \%$ & 1.28 & 18.25 & 0.17 & 402.04 \\
\hline
\end{tabular}

6.2. Comparative analysis of finite element analyzing and test results of SSPCs

\subsubsection{Deformation}

The test specimen of SSPC1, with the initial PT force of $0.25 T_{\mathrm{y}}$, was used as an example. When the story drift of the test and the finite element analysis reached $0.68 \% \mathrm{rad}$ and $0.6 \% \mathrm{rad}$, respectively, a gap opening appeared between the beam and column. Then, as the story drift increased, the opening width and bearing capacity of the connection continued to increase; the maximum opening width was $20.63 \mathrm{~mm}$ and $19.97 \mathrm{~mm}$, and the ultimate bearing capacity of the connection reached $363.68 \mathrm{kN}$ and $384.43 \mathrm{kN}$, respectively. After returning to the equilibrium position, the maximum residual opening width of the test and finite element analysis was $0.94 \mathrm{~mm}$ and $0.10 \mathrm{~mm}$, respectively, as shown in Figure 20(a)-(d)

In the loading process, the variation trends of deformation for both SSPCs were basically the same; the connection deformation results of test and finite element analysis can be seen in Table 5. The residual opening width of both connections was relatively small, and the post-seismic self-centering mechanism was realized. The test and finite element analysis results below indicated that in the cyclic loading process, the deformation of SSPCs achieved by finite element analysis was very close to that of the test.

\subsubsection{Hysteresis loop and changes in stiffnes}

The moment values of the two specimens can be calculated from the theoretically derived Eq. 1. Figure 21(a)-(b) shows the comparison of the moment-gap opening rotation hysteresis loops of both specimens from the theoretical formula calculation, finite element numerical simulation, and test results. Generally speaking, the hysteresis loops, hysteresis loop areas, and changing trends of the two test specimens obtained by finite element numerical simulation and theoretical formula calculation were basically consistent with those of the test results, indicating that the method adopted in the finite element simulation reflected the real situation of the specimens. The finite element analysis results were realistic and reliable and can be used as a basis for subsequent analysis. The difference of theoretical formula calculation and experimental results is small, and theoretical formula calculation can be used as the basis for future design and analysis.
Taking SSPC1 as an example, the gap opening at the beam-column contact interface occurred when the story drift reached $0.68 \% \mathrm{rad}$ and $0.6 \% \mathrm{rad}$, respectively, for the experiment and finite element analysis; correspondingly, the gap opening rotation were $0.22 \% \mathrm{rad}$ and $0.30 \% \mathrm{rad}$, respectively, while the theoretical opening rotation angle was zero. The imminent gap opening moment of the experiment, finite element and theoretical calculations was $356.9 \mathrm{kN} \cdot \mathrm{m}$, $392.9 \mathrm{kN} \cdot \mathrm{m}$, and $396.8 \mathrm{kN} \cdot \mathrm{m}$, respectively. When the story drift reached $0.05 \mathrm{rad}$, the maximum gap opening rotation increased to $4.43 \% \mathrm{rad}$ and $4.29 \% \mathrm{rad}$ for the experiment and finite element analysis, respectively. Taking the experiment maximum gap opening rotation as the theoretical analysis value, the ultimate moment reached $772.8 \mathrm{kN} \cdot \mathrm{m}, 816.9 \mathrm{kN} \cdot \mathrm{m}$, and $852.8 \mathrm{kN} \cdot \mathrm{m}$, respectively. Upon unloading, the maximum residual rotation was $0.20 \% \mathrm{rad}$ and $0.02 \% \mathrm{rad}$ respectively. The imminent gap opening moment and ultimate moment of the connection from the finite element and theoretical calculations were basically the same as those of the experimental results, while the gap opening rotation obtained from the finite element calculation was more consistent with the experimental result.

\subsubsection{PT force variation}

Figure 22(a)-(b) shows that the PT force variations for S5 (as shown in Figure 10) of the SSPCs from the finite element analysis, theoretical formula calculation and experiment were the same. The beam and the column disengaged as the story drift increased, and the PT force gradually increased after the disengagement. The maximum PT force from the experiment, finite element and theoretical calculations was $381.7 \mathrm{kN}, 384.9 \mathrm{kN}$ and $387.3 \mathrm{kN}$, respectively. When the story drift returned to zero at the end of each loading cycle, the PT force also basically returned to the initial prestressed value. The prestressed value in the finite element analysis was higher than the actual test value because factors such as the retraction of the core wire in the prestressed strand and anchor clip plate sliding were not considered. The theoretical formula calculation took into account the reduction of the PT force due to the anchor end deformation, as a result the theoretical formula calculation results were more consistent with the experimental results. 


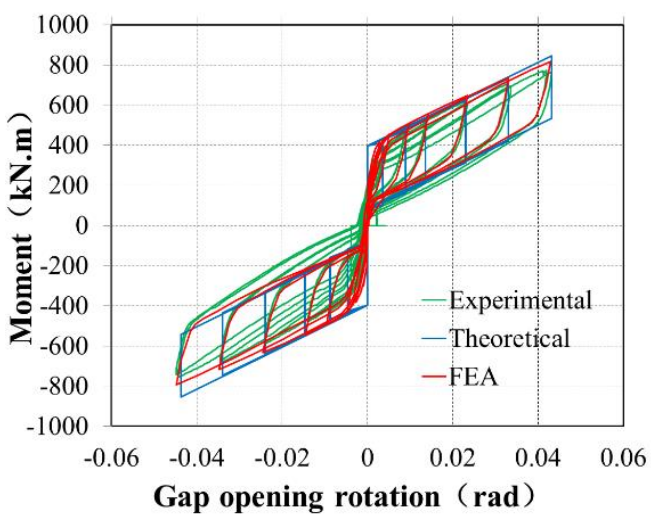

(a) SSPC1

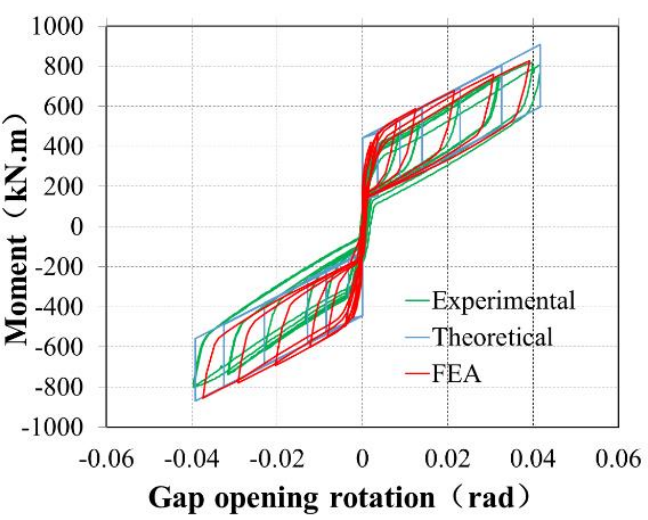

(b) SSPC2

Fig. 21 Comparison of experimental, theoretical and FEA moment-gap opening rotation relationship for Specimens

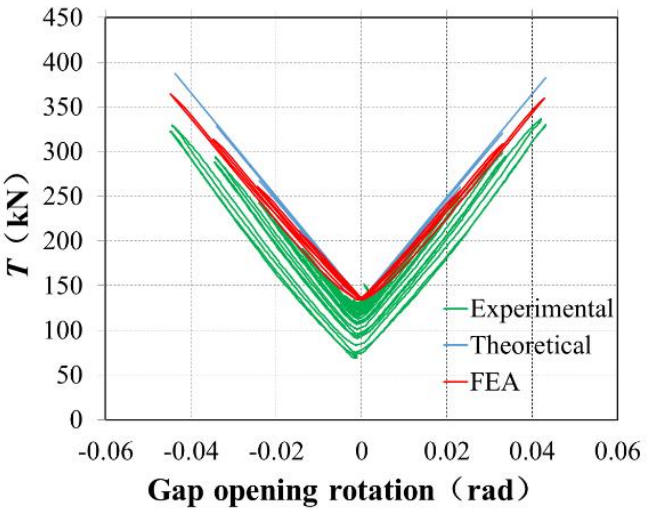

(a) SSPC1

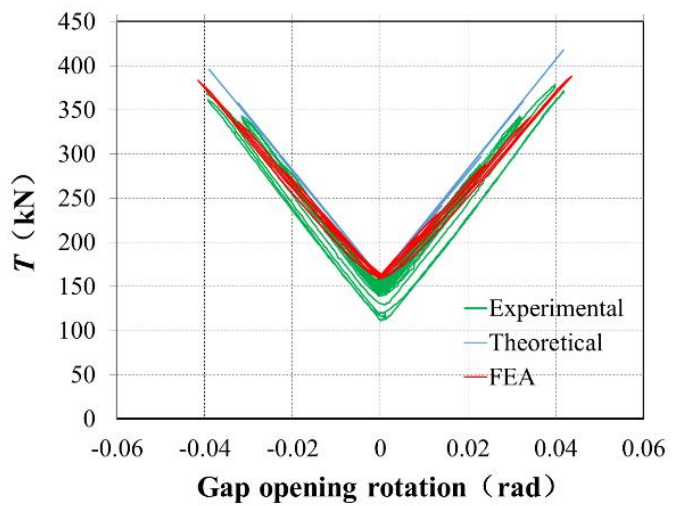

(b) SSPC2

Fig. 22 Comparison of experimental, theoretical and FEA PT force-gap opening rotation relationship for S5 of specimens

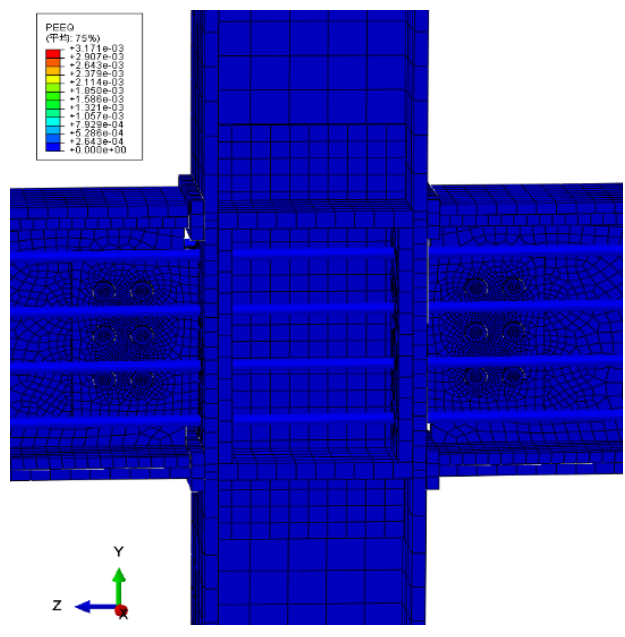

(a) $\theta=0.01 \mathrm{rad}$

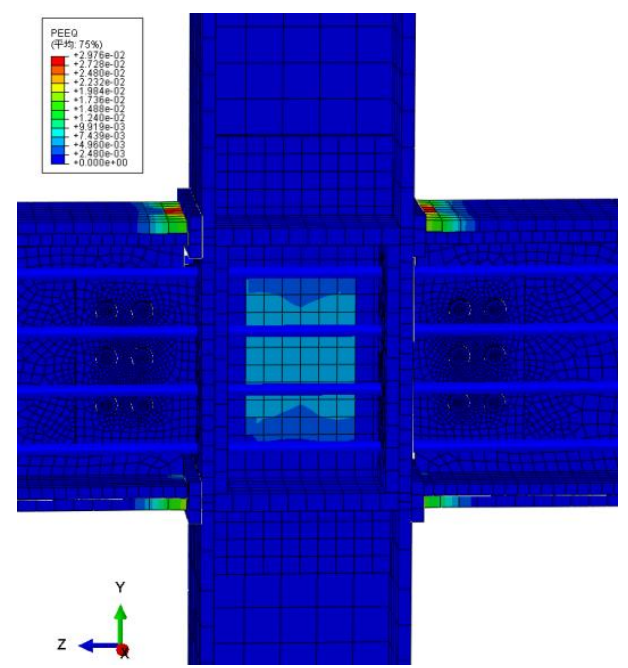

(b) $\theta=0.05 \mathrm{rad}$

Fig. 23 PEEQ diagram of SSPC2

\subsubsection{Plasticity development}

The connection SSPC2 with a higher initial PT force was taken as an example to conduct the plasticity analysis. The equivalent plastic strain (PEEQ) of the beam and the column of SSPC2 is shown in Figure 23(a)-(b). The PEEQ became zero when the story drift $\theta$ was $0.01 \mathrm{rad}$; the connection was in an elastic state. At $0.015 \mathrm{rad}$ loading level, the maximum plasticity appeared at the beam flange reinforcing plate, for which the PEEQ was $1.58 \times 10^{-3} \varepsilon$; the beam flange also showed plastic strain, which is consistent with the test result. As the story drift gradually increased, the plastic strain at the beam flange reinforcing plate gradually accumulated. At $0.05 \mathrm{rad}$ loading level, the maximum PEEQ reached $2.97 \times 10^{-2} \varepsilon$ and the maximum plastic strain of the beam and the column increased to $1.4 \times 10^{-2} \varepsilon$ and $6.5 \times 10^{-3} \varepsilon$, respectively. Aside from the beam flange reinforcing plate and beam flange, the parts basically did not show plastic development in the entire test process. The connection strain variations of the main components in the finite element analysis were basically same as those in the experiment. 


\section{Conclusions}

In this paper, the theoretical formula derivation, experiment study, and finite element numerical simulation were conducted for two cross-shaped prefabricated beam-column connections with short strands. The impact of adjusting the initial PT force to the load bearing capacity, gap-opening deformation and energy dissipation capability of the connection were examined. The conclusions are as follows:

1. The prefabricated beam-column connection with short strands has the advantage of avoiding on-site aerial tension and requiring only high-strength bolts for the assembly in the actual construction process. The hysteresis loops show an obvious double flag shape, indicating that this type of connection realizes a relatively favorable self-centering mechanism.

2. As the initial prestressed forces of the connection increases, the initial stiffness, post-gap opening stiffness, imminent gap opening moment and maximum PT force all increase to a certain degree; while the maximum gap opening width gradually decreases, and the energy dissipation coefficient shows a descending trend. Both of the specimens satisfy the basic requirement of having an energy dissipation coefficient greater than 0.25 during the experiment.

3 . When the story drift reaches the specification defined by $0.02 \mathrm{rad}$, the reduction of PT force for the connection is within $15 \%$. The reduction in PT force is mainly concentrated after the story drift of $0.03 \mathrm{rad}$, but the residual PT force still maintain a certain stiffness and structural failure does not occur.

4. Aside from the resulting plasticity of the beam flange reinforcing plate and beam flange closer to the column, the strain development of both connections remained at a relatively low level and the typical positions such as column flange and web are basically in an elastic state.

5. Through comparative analysis of the results from the theoretical formula calculation and finite element analyses to the experimental results, the feasibility of the theoretical formula derivation and finite element analyses was verified. The two methods not only lay the foundation for further research on this type of connections but also provide a reference for structural design.

\section{Acknowledgements}

The research in this paper was supported by the National Key Basic Research and Development Program of China under Grant No.2017YFC0703806 and Natural Science Foundation of China under Grant No.51778036

\section{References}

[1] American Institute of Steel Construction (AISC-341), Seismic Provisions for Structural Steel Buildings, 2005

[2] Collins J.H. and Filiatrault A., "Application of posttensioned energy dissipating (PTED) connections in steel moment-resisting frames", Dept. of Structural Engineering, Univ. of California, San Diego.

[3] Garlock M.M., Ricles J.M. Sause R., Peng S.W., Zhao C. and Lu L.W., "Post-tensioned seismic resistant connections for steel frames", Structural Stability Research Council Conference Workshop, Rolla Missouri. Structural Stability Research Council, 1998.

[4] Ricles J.M., Sause R., Garlock M.M. and Zhao C., "Post-tensioned seismic-resistant connections for steel frames", Journal of Structural Engineering, 127(2), 113-121, 2001.

[5] Ricles J.M., Sause R., Peng S. and Lu L., "Experimental evaluation of earthquake resistan post-tensioned steel connections", Journal of Structural Engineering, 128(7), 850-859, 2002.

[6] Garlock M.M., "Design, analysis, and experimental behavior of seismic resistant posttensioned steel moment resisting frames", Lehigh University, Bethlehem, Pennsylvania, 2002.

[7] Garlock M.M., Ricles J.M. and Sause, R., "Cyclic load tests and analysis of bolted top-andseat angle connections", Journal of Structural Engineering, 129(12), 1615-1625, 2003.

[8] Garlock M.M., Ricles J.M. and Sause R., "Experimental studies on full-scale post-tensioned steel connections", Journal of Structural Engineering, 131(3), 438-448, 2005.

[9] Christopoulos C., "Self-centering post-tensioned energy dissipating (PTED) steel frame for seismic regions", University of California at San Diego, San Diego, 2002.

[10] Christopoulos C., Filiatrault A. and Folz B., "Seismic response of self-centering hysteretic SDOF systems", Earthquake Engineering and Structural Dynamics, 31(5), 1131-1150, 2002

[11] Rojas P., Ricles J.M. and Sause R., "Seismic performance of post-tensioned steel moment resisting frames with friction devices", Journal of Structural Engineering, 131(4), 529-540, 2005.

[12] Wolski M., Ricles J.M. and Sause R., "Experimental study of a self-centering beam-column connection with bottom flange friction device", Journal of Structural Engineering, 135(5), 479-488, 2009.

[13] Lin Y.C., Sause R. and Ricles J. M., "Seismic performance of steel self-centering, momentresisting frame: hybrid simulations under design basis earthquake", Journal of Structural Engineering, 139(5), 1823-1832, 2013.

[14] Lin Y.C., Sause R. and Ricles J.M., "Seismic performance of a large-scale steel self-centering moment-resisting frame: MCE hybrid simulations and quasi-static pushover tests", Journal of Structural Engineering, 139(7), 1227-1236, 2013.

[15] Tzimas A., Dimopoulos A., Karavasilis T., "EC8-based seismic design and assessment of self-centering post-tensioned steel frames with viscous dampers", Journal of Constructional Steel Research, 60-73, 2015.

[16] Wang W., Fang C. and Liu J., "Self-centering beam-to-column connections with combined superelastic SMA bolts and steel angles", Journal of Structural Engineering, 143(2), 04016175, 2017.

[17] Jahangiri A., Behnamfar F., and Jahangiri M., "Introducing the innovative post-tensioned connection with the rigid steel node" KSCE Journal of Civil Engineering, 21(4), 1247-1255, 2017.

[18] Zhang Y.X., Wang Z.Y., Zhao W., Zhao W.Z., "A pseudo-dynamic test study on a selfcentering prefabricated steel frame with a column base connected by semi-rigid joints", Advanced Steel Construction, 12(3), 296-315, 2016.

[19] Zhang Y.X., Li Z.X., Zhao W.Z., Li R., Li J.R., "A performance study of beam column connections of self-centering steel frame with U-shaped steel dampers", Advanced Steel Construction, 12(4), 446-465, 2016.

[20] Zhang A.L., Zhang Y.X., Li R. and Wang Z.Y., "Cyclic behavior of a prefabricated selfcentering beam-column connection with a bolted web friction device", Engineering Structures, 111,185-198, 2016 